\title{
Management of Cervico-Vaginal Prolapse in a Pre-partum Crossbred Cow: A Case Report
}

\author{
M. Baruti ${ }^{1}$, R. Deka ${ }^{1}$, M. Bhuyan ${ }^{1}$, I. Gayari ${ }^{2 *}$ and D. Bhuyan ${ }^{1}$ \\ ${ }^{1}$ Department of ARGO, College of Veterinary Science, \\ $A A U$, Khanapara, Guwahati-781022, India \\ ${ }^{2}$ DBT Twinning Project, Department of ARGO, \\ College of Veterinary Science, AAU, Khanapara, Guwahati-781022, India \\ *Corresponding author
}

A B S T R A C T

\section{Keywords}

Crossbred cow,

Veterinary,

Numbness,

Pelvic sensation,

Article Info

Accepted:

11 June 2020

Available Online:

10 July 2020
Seven years old Crossbred Cow was presented in Teaching Veterinary Clinical Complex showing the signs of Cervico-Vaginal Prolapse. A thorough examination was done and on per rectal examination the foetus along with intact placenta could be palpated with positive fetal reflexes. The cow was administered $5 \mathrm{ml}$ of Lignocaine hydrochloride (2\%) through caudal epidural space to prevent straining and numbness of pelvic sensation in order to insert the prolapsed mass back into the vagina. Supportive therapy using Ceftiofur ( $15 \mathrm{mg} / \mathrm{kg}$ body wt. i $/ \mathrm{m})$, Meloxicam $(0.5 \mathrm{mg} / \mathrm{kg}$ body wt. $\mathrm{i} / \mathrm{m}$ ) and DNS (3 liter $\mathrm{i} / \mathrm{v}$ ) was administered and Caesarian section was performed the following day and a healthy calf was born following $\mathrm{C}$ section.

\section{Introduction}

Large ruminants suffering from Cervicovaginal prolapse is often comes across by veterinarians. Ruminants like Cattle and Buffalo may suffer from cervico vaginal prolapsed. Extensive elaboration of incidence and symptoms in cows has been documented (Roberts, 1971 and Arthur et al., 1989). Suturing the vulvar lips using various suture patterns although present initial eversion of vagina into the vestibule is difficult to achieve. The present study was carried out to evaluate the clinical management of Cervico-vaginal prolapse in a pregnant cow by application of retention sutures.

\section{Materials and Methods}

A five years old Crossbred Cow was presented in Teaching Veterinary Clinical Complex showing the signs of Cervico- 
Vaginal Prolapse. The owner reported that the cow was at the last stage of pregnancy and has been straining since last two days.

On the day of reporting to TVCC, Khanapara the owner observed prolapsed mass was hanging from the vaginal region. The animal was exhibited signs of discomfort and was constantly straining (Fig. 1). A thorough examination was done and on per rectal examination the foetus along with intact placenta could be palpated.

The cow was administered $5 \mathrm{ml}$ of Lignocaine hydrochloride (2\%) through 1st inter coccygeal space to prevent straining and numbness of pelvic sensation in order to insert the prolapsed mass back into the vagina. As soon as anesthetic took its action prolapsed part was thoroughly cleaned using water to get rid of any soil or dirt sticking to the mass.

The mass was then washed again with normal saline and potassium permanganate solution. The prolapsed mass was lifted by hands to the level of vagina and was pushed slowly back into the vagina. Vulva retention suture using gauge bandange of $3 / 4 \mathrm{~cm}$ thickness was used as suturing technique with Buhners' needle (Fig. 1, 2 and 3).

Vulval suture was done near the hairline starting from dorsal commissure to ventral commissure. Bhunner's needle carrying the suturing material was passed vertically from one side of the vulval lips from upper to lower commissure under the skin.

Likewise the second suturing was made in the other side of the vulval lips in the same way. The terminal portion of each side of suture was tied together ventrally and considerable care was taken to keep the vaginal lips in apposition without gapping through a flexible knot (Fig. 2). The advantage of this technique is that, the vaginal exploration can be made only by losing the knot with no further tampering of the external genitalia. Supportive therapy using Ceftiofur $(15 \mathrm{mg} / \mathrm{kg}$ body wt. i/m), Meloxicam $(0.5 \mathrm{mg} / \mathrm{kg}$ body wt. $\mathrm{i} / \mathrm{m}$ ) and DNS (3 liter $\mathrm{i} / \mathrm{v})$ was administered on 1st day, followed by Ceftiofur and Meloxicam for another 5 days. D-Mag spay was applied topically over the external vulval lips as a fly repellant. Since the cow has attain full term of pregnancy the induction of parturition with Cloprostenol 250 mcg (Pragma 2ml) IM and Dexamethasone 20 mg IM (Dexona $10 \mathrm{ml}$ ) IM was done. The pervaginal examination for cervical opening was monitored within 8 hours intervals.

After 24 hours since the cervical opening was closed and condition leading to an incomplete cervical dilation, the cow was subjected for $\mathrm{C}$ section. $\mathrm{C}$ section was performed on the right leteral recumbancy and an oblique incision made on the lower caudal flank region. A healthy calf was delivered without any difficulties (Fig. 3).

The entire incision layer sutured with absorbable polydiaxone size 2 and skin suture is done by size 2silk. After operation cervical dilator was used for proper expulsion of placenta. Post operatively Flunixin @ 2,2 $\mathrm{mg} / \mathrm{kg}$, antibiotic Cefiofur, antihistamin, oral proteolytic enzyme was given for 5 days. No further symptoms of prolapse or any clinical deviation was marked after expulsion of a live fetus, the knot was retained to avoid further uterine prolapse and the suture material was removed after 7 days.

\section{Results and Discussion}

In cattle eversion and prolapse of the vagina, with or without prolapse of the cervix, occurs most commonly in mature females in the last trimester of pregnancy and seldom occurs in primipara. 


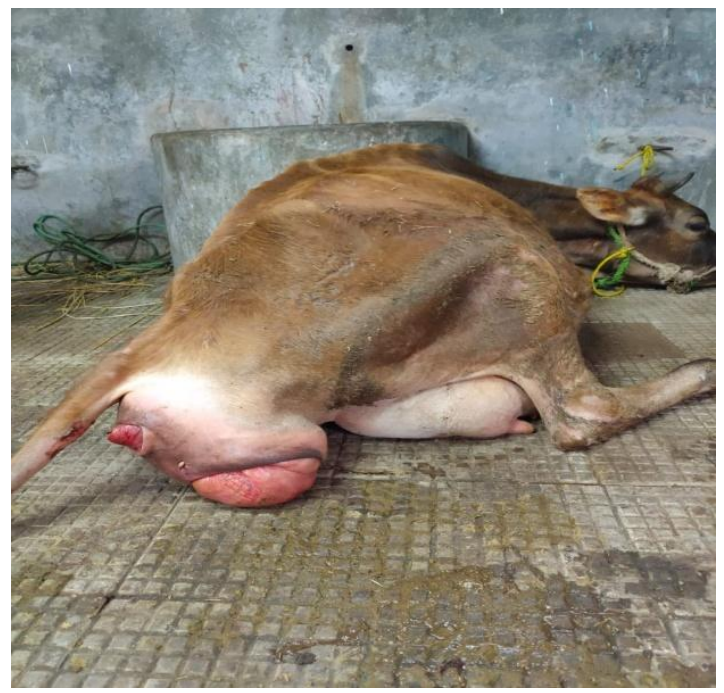

Fig.1 Cervico vaginal prolaps

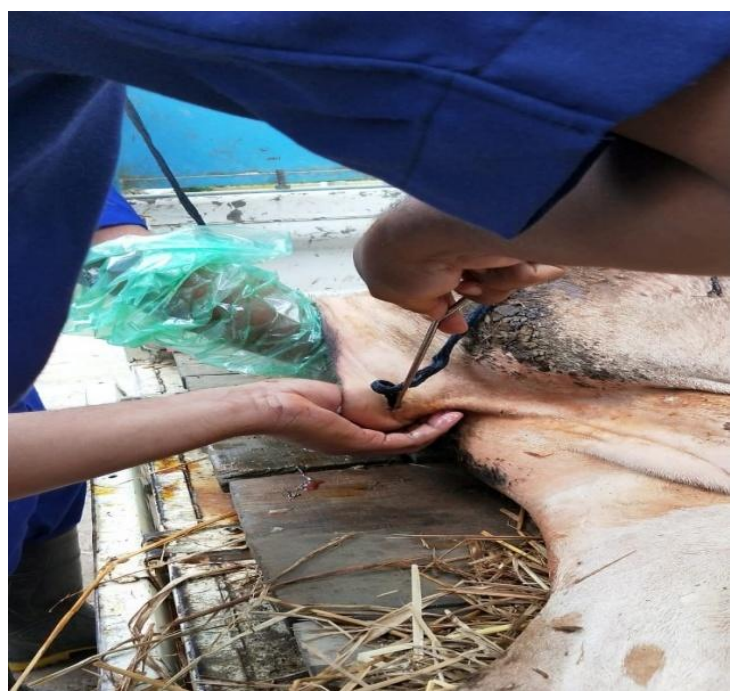

Fig.2 Buhner technique

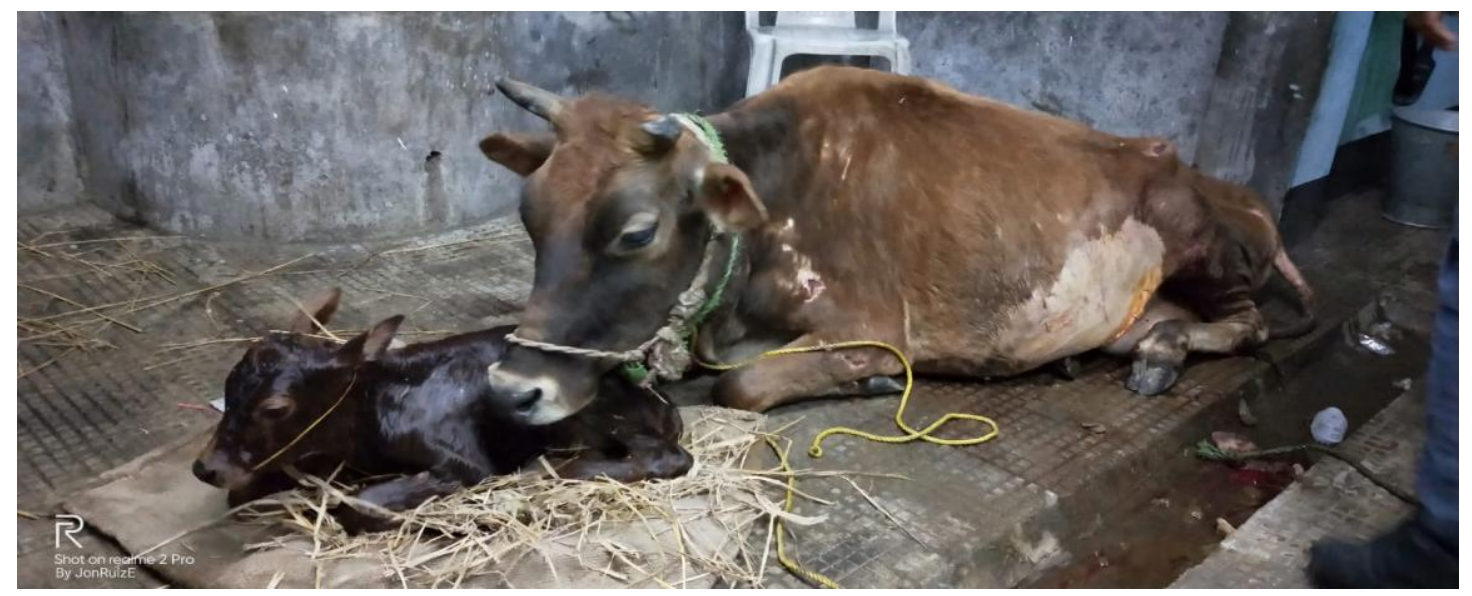

Fig.3 Live fetus after $\mathrm{C}$ section

However, over relaxation of pelvic structure, flaccid uterus and hyperestrogenism are considered as predisposing factors (Jackson, 2004 and Hanie, 2006). The present suturing technique is more efficient and suitable in large ruminants where re-examination is sometimes needed and could be successfully employed in recurrent cervicovaginal prolapse.

\section{References}

Arthur, G.H., Noakes D.E. and Pearson H. 1989. Veterinary Reproduction and Obstetrics. (Theriogenology). 6th edn., ELBS., Bailliere Tindalle, London, UK, pp. 295- 300.

Jackson, P.G.G. 2004. Postparturient Problems in Large Animals. Hand Book of Veterinary Obstetrics. 2nd Edn., Elsevier Saunders, pp:209-231.

Patra, B. K., Nahak A. K., Dash, S. K., Sahu, S. S., Das, S. P., Das, S. and Mohanty, D.N. 2014. Cervico Vaginal Prolapse in a Pregnant Cow and Its Management A Case Report. International Journal of Livestock Research, 4(5):55-59

Roberts, S.J. 1971. Veterinary Obstetrics and Genital Diseases. $2^{\text {nd }}$ Ed. Edwards Brothers, Inc., AnnArbor, Michigan,pp:308-313. 


\section{How to cite this article:}

Baruti, M., R. Deka, M. Bhuyan, I. Gayari and Bhuyan, D. 2020. Management of CervicoVaginal Prolapse in a Pre-partum Crossbred Cow: A Case Report. Int.J.Curr.Microbiol.App.Sci. 9(07): 936-939. doi: https://doi.org/10.20546/ijcmas.2020.907.108 